\title{
Socio-Demography and Medical History as Predictors of Health-Related Quality of Life of Breast Cancer Survivors
}

\author{
Amutha Ramadas ${ }^{1}$, Ahmad Munir Qureshi ${ }^{1 *}$, Nisha Angela Dominic ${ }^{1}$, Nevein \\ Philip Botross ${ }^{1}$, Amgad Riad ${ }^{2}$, Valliammai Jayanthi Thirunavuk Arasoo ${ }^{1}$, Soman \\ Elangovan $^{1}$
}

\begin{abstract}
Background: Even after completion of conventional treatment, breast cancer survivors continue to exhibit a variety of psychological and physical symptoms, affecting their quality of life. The study aimed to investigate the relationship between socio-demography, medical characteristics and health-related quality of life (HR-QOL) of a sample of breast cancer survivors in Malaysia. Materials and Methods: This pilot cross-sectional survey was conducted among breast cancer survivors $(n=40)$ who were members of Breast Cancer Support Group Centre Johor Bahru. A validated self-administered questionnaire was used to identify the relationships between socio-demography, medical characteristics and HR-QOL of the participants. Results: Living with family and completion of treatment were significant predictive factors of self-rated QOL, while living with family and ever giving birth significantly predicted satisfaction with health and physical health. Psychological health had moderate correlations with number of children and early cancer stage. Survivors' higher personal income (>MYR4,500) was the only significant predictor of social relationship, while age, income more than MYR4,500 and giving birth significantly predicted environment domain score. Conclusions: The findings suggested the survivors coped better in all four HR-QOL domains if they were married, lived with family, had children and were employed.
\end{abstract}

Keywords: Breast cancer survivors - health-related quality of life - Malaysia

Asian Pac J Cancer Prev, 16 (4), 1479-1485

\section{Introduction}

Breast cancer $(\mathrm{BCa})$ is the most common cancer among Malaysian women, accounting for $16.5 \%$ of all registered cancer cases among Malaysian Peninsular women (National Cancer Registry, 2007). The treatment for $\mathrm{BCa}$ has improved by leaps and bounds in recent years coupled with advances in early detection, which have led to reduced mortality rate. The overall survival rate among Malaysian BCa survivors was reported to be between $43.5 \%$ and $75.7 \%$ (Taib et al., 2011; Ibrahim et al., 2012; Abdullah et al., 2013). We are now facing the issue of younger BCa survivors who may have many years of morbidity ahead.

In addition, the diagnosis of cancer still invokes the feeling of stress, fear and uncertainty (Yusuf et al., 2013). After completing treatment for $\mathrm{BCa}$, these women continue to experience a variety of psychological and physical symptoms, need information and support (Cappiello et al., 2007). Longitudinal studies have shown impaired quality of life (QOL) of survivors beyond fifth year of diagnosis (Koch et al., 2013), highlighting the dire need for more focus on a continuous support program for $\mathrm{BCa}$ survivors. Research has shown poor coping in younger compared older survivors with regards to their families, work, appearance and body image (Thewes et al., 2004). Such studies are limited in Malaysia or South East Asia.

While younger women had better physical functioning, older women did better in terms of both emotional wellbeing and communication with partner. Younger women who just completed BCa treatment reported worse global QOL and emotional well-being, and more disease specific concerns and depression compared to older survivors (Wenzel et al., 1999). Research findings have indicated that the diagnosis of $\mathrm{BCa}$ is associated with heightened levels of negative emotions and psychological distress, especially symptoms of anxiety and depression. Elevated symptoms of anxiety and depression near the time of diagnosis are typically reported in $30 \%$ to $40 \%$ of patients, a rate that is approximately three to four times of the general population (Epping-Jordan et al., 1999).

Hence there is a need to improve their quality of life (QOL), and a comprehensive multidimensional assessment of psychosocial factors will further improve 
Amutha Ramadas et al

BCa survivors' overall level of well-being. The study aimed to investigate the relationship between sociodemography, medical characteristics and health-related quality of life (HR-QOL) of a sample of BCa survivors in Malaysia.

\section{Materials and Methods}

A pilot cross-sectional survey was conducted to identify the relationship between socio-demography, medical characteristics and HR-QOL of BCa survivors. The study was conducted at the Breast Cancer Support Group Centre Johor Bahru (BCSGJB). The ethical approval to conduct the study was obtained from Monash University Human Ethics Committee (CF14/8142014000330) prior to data collection.

The survivors from BCSGJB were invited to participate in the study after obtaining written consent. No selection restriction was imposed with regards to ethnicity, histology of $\mathrm{BCa}$, disease stage, and demographic characteristics. Women who could not self-administer the study questionnaire were excluded. All of the participants were assured of confidentiality.

\section{Study instrument}

Data were collected using a self-administered structured questionnaire that comprised of questions on the participants' socio-demography, medical characteristics and HR-QOL. Socio-demographic data collected included age, marital status, education level, house-hold income, employment status, type of accommodation and number of children, and medical characteristics consisting of age of onset, disease stage and completion of treatment were also obtained. We assessed the HR-QOL using the validated WHOQOL-BREF with items on overall QOL, satisfaction with health, experience during past 4 weeks, ability to look after oneself and manage challenges, along with negative feelings she may have experienced. The questionnaire took approximately 20 minutes to be completed.

\section{Statistical analysis}

The independent variables were the socio-demographic and medical characteristics, while the HR-QOL was the dependent variable. Descriptive statistics (frequency, percentages, mean, standard deviation and range) were used to describe the data. Association between the factors and HR-QOL were determined using chi-square analysis,

\section{Table 1. Sociodemography and Medical History of the Study Participants}

\begin{tabular}{|c|c|c|}
\hline \multirow[t]{4}{*}{ Age } & Mean (SD) & $57.5(9.8)$ \\
\hline & $<50$ & $13(32.5)$ \\
\hline & $50-59$ & $8(20.0)$ \\
\hline & $>60$ & $19(47.5)$ \\
\hline \multirow[t]{3}{*}{ Marital status } & Married & $32(80.0)$ \\
\hline & Single & $4(10.0)$ \\
\hline & Divorced/widowed & $4(10.0)$ \\
\hline \multirow[t]{3}{*}{ Education } & No education/primary & $6(15.0)$ \\
\hline & Secondary & $23(57.5)$ \\
\hline & Tertiary & $11(27.5)$ \\
\hline \multirow[t]{3}{*}{ Income (MYR) } & $<1,800$ & $10(25.0)$ \\
\hline & $1,801-4,500$ & $19(47.5)$ \\
\hline & $>4,500$ & $11(27.5)$ \\
\hline \multirow[t]{4}{*}{ Occupation } & Unemployed & $14(35.0)$ \\
\hline & Full-time & $7(17.5)$ \\
\hline & Part-time & $4(10.0)$ \\
\hline & Retired & $15(37.5)$ \\
\hline \multirow[t]{2}{*}{ Living arrangement } & Living alone & $2(5.0)$ \\
\hline & Living with family & $38(95.0)$ \\
\hline \multirow[t]{2}{*}{ Ever given birth } & Yes & $34(85.0)$ \\
\hline & No & $6(15.0)$ \\
\hline \multirow[t]{3}{*}{ Number of children } & None & $10(25.0)$ \\
\hline & $1-2$ & $17(42.5)$ \\
\hline & $>3$ & $13(32.5)$ \\
\hline \multirow[t]{2}{*}{ Stage of cancer } & Early & $33(82.5)$ \\
\hline & Late & $7(17.5)$ \\
\hline \multirow[t]{4}{*}{ Age at diagnosis (years) } & $<40$ & $7(17.5)$ \\
\hline & $40-49$ & $15(37.5)$ \\
\hline & $50-59$ & $11(27.5)$ \\
\hline & $>60$ & $7(17.5)$ \\
\hline \multirow[t]{4}{*}{ Duration since diagnosis (years) } & $<5$ & $23(57.5)$ \\
\hline & $6-10$ & $7(17.5)$ \\
\hline & $11-15$ & $4(10.0)$ \\
\hline & $>15$ & $6(15.0)$ \\
\hline \multirow[t]{2}{*}{ Completion of treatment } & Yes & $35(87.5)$ \\
\hline & No & $5(12.5)$ \\
\hline \multirow[t]{3}{*}{ Duration since completion of treatment (years) } & $<3$ & $13(37.1)$ \\
\hline & $3-5$ & $6(17.1)$ \\
\hline & $>5$ & $16(45.7)$ \\
\hline
\end{tabular}


Socio-Demography and Medical History as Predictors of Health-Related Quality of Life of Breast Cancer Survivors

correlations and multiple linear regressions. The statistical analysis was performed with IBM $^{\circledR}$ SPSS $^{\circledR} 20.0$, and statistical significance was set at $\mathrm{p}=0.05$.

\section{Results}

Study participants

The characteristics of study participants are presented in Table 1. Majority of the participants (47.5\%) was above the age of 60 years. Eighty percent of them were married. Many (85\%) had at least secondary level education, with $27.5 \%$ of them had full-time or part-time employment. Most (47.5\%) belonged to middle income group (MYR1800-4500), followed by higher income group (>MYR4500) $27.5 \%$, and then by low income group (>MYR1800) 25\%. Almost all (95\%) were living with their families and only a few lived alone (5\%).

Majority had delivered before $(85 \%)$ and but some had no surviving child/children $(25 \%)$. Most $(82.5 \%)$ were diagnosed with early cancer stage, and the rest were picked at late stage (17.5\%). More than half the women interviewed were diagnosed less than five years ago, and a small percentage $(12.5 \%)$ of the survivors was still undergoing treatment at the time of interview. More than

Table 2. Mean Difference in HR-QOL Domain Scores According to Sociodemography and Medical History of Study Participants

\begin{tabular}{|c|c|c|c|c|c|c|}
\hline \multirow{2}{*}{$\frac{\text { Domain Factor }}{\text { Physical Health }}$} & & \multirow[t]{2}{*}{ Mean (SD) } & \multirow[t]{2}{*}{$\mathrm{P}$} & \multicolumn{2}{|c|}{ Pairwise comparison a Mean difference (95\% CI) } & \multirow[t]{2}{*}{$\mathrm{P}$} \\
\hline & & & & & & \\
\hline \multirow[t]{3}{*}{ Marital status } & Married & $63.6(8.8)$ & $0.042 *$ & Married vs Single & $12.2(0.85-23.59)$ & $0.033^{*}$ \\
\hline & Single & $51.4(10.6)$ & & & & \\
\hline & rced / widowed & $62.9(6.0)$ & & & & \\
\hline \multirow[t]{4}{*}{ Occupation } & Unemployed & $62.2(8.5)$ & $0.006^{*}$ & Unemployed $v s$ part-time & $13.1(0.57-25.55)$ & $0.038^{*}$ \\
\hline & Full-time & $68.6(4.0)$ & & Full-time $v s$ part-time & $19.4(5.62-33.23)$ & $0.022 *$ \\
\hline & Part-time & $49.1(12.6)$ & & & & \\
\hline & Retired & $63.3(9.3)$ & & & & \\
\hline \multirow[t]{2}{*}{ Living arrangement } & Living alone & $38.9(3.2)$ & $<0.001 * *$ & & & \\
\hline & With family & $63.6(7.7)$ & & & & \\
\hline \multirow[t]{2}{*}{ Ever given birth } & Yes & $64.7(6.9)$ & $<0.001 * *$ & & & \\
\hline & No & $48.8(10.2)$ & & & & \\
\hline \multirow[t]{2}{*}{ Stage } & Early & $63.9(8.3)$ & $0.023^{*}$ & & & \\
\hline & Late & $55.2(11.3)$ & & & & \\
\hline \multicolumn{7}{|l|}{ Psychological } \\
\hline \multirow{3}{*}{ Income (MYR) } & $<1,800$ & $56.8(5.8)$ & $0.017 *$ & $<1,800 v s>4,500$ & $-8.7(-15.86--1.44)$ & $0.015^{*}$ \\
\hline & $1,801-4,500$ & $62.9(7.2)$ & & & & \\
\hline & $>4,500$ & $65.5(6.7)$ & & & & \\
\hline \multirow[t]{4}{*}{ Occupation } & Unemployed & $62.7(8.4)$ & $0.048^{*}$ & Full-time $v s$ part-time & $12.4(0.80-23.96)$ & $0.032 *$ \\
\hline & Full-time & $67.0(4.5)$ & & & & \\
\hline & Part-time & $54.7(6.3)$ & & & & \\
\hline & Retired & $61.2(6.2)$ & & & & \\
\hline \multirow{2}{*}{ Living arrangement } & Living alone & $49.3(1.9)$ & $0.010 *$ & & & \\
\hline & With family & $62.7(6.9)$ & & & & \\
\hline \multirow[t]{2}{*}{ Ever given birth } & Yes & $63.5(6.8)$ & $0.002 *$ & & & \\
\hline & No & $53.8(4.6)$ & & & & \\
\hline \multirow[t]{3}{*}{ Number of children } & None & $53.8(4.6)$ & $0.012 *$ & None $v s$ 1-2 & $-9.3(-17.00--1.57)$ & $0.015^{*}$ \\
\hline & $1-2$ & $63.1(6.4)$ & & None $v s>3$ & $-9.6(-17.62--1.60)$ & 0.016 \\
\hline & $>3$ & $63.4(7.6)$ & & & & \\
\hline \multirow[t]{2}{*}{ Stage } & Early & $63.2(7.1)$ & $0.034 *$ & & & \\
\hline & Late & $56.8(6.3)$ & & & & \\
\hline \multicolumn{7}{|l|}{ Social relationship } \\
\hline \multirow[t]{2}{*}{ Ever given birth } & Yes & $63.7(10.4)$ & $0.048^{*}$ & & & \\
\hline & No & $55.1(5.5)$ & & & & \\
\hline \multicolumn{7}{|l|}{ Environment } \\
\hline \multirow[t]{2}{*}{ Marital status } & Married & $64.2(7.6)$ & $0.013^{*}$ & Married $v s$ Single & $11.2(1.95-20.42)$ & $0.015^{*}$ \\
\hline & Single & $53.0(4.8)$ & & & & \\
\hline \multicolumn{2}{|c|}{ Divorced / widowed } & $59.0(3.5)$ & & & & \\
\hline Living arrangement & Living alone & $51.0(4.2)$ & $0.030^{*}$ & & & \\
\hline & With family & $63.2(7.5)$ & & & & \\
\hline Ever given birth & Yes & $64.2(7.2)$ & $0.001 *$ & & & \\
\hline & No & $53.3(3.7)$ & & & & \\
\hline Number of children & None & $53.3(3.7)$ & $0.005^{*}$ & None vs 1-2 & $-11.8(-20.00--3.63)$ & $0.003^{*}$ \\
\hline & $1-2$ & $65.2(7.2)$ & & None $v s>3$ & $-9.4(-17.92--0.96)$ & $0.027 *$ \\
\hline & $>3$ & $62.8(7.7)$ & & & & \\
\hline Stage & Early & $63.6(7.4)$ & $0.042 *$ & & & \\
\hline & Late & $57.1(8.2)$ & & & & \\
\hline
\end{tabular}

*Significant at $\mathrm{p}<0.05 ; * *$ significant at $\mathrm{p}<0.00$; aBonferonni post-hoc analysis done only for independent variables with more than 2 categories . Only significant results are shown 
$45 \%$ completed the treatment for more than five years.

\section{HR-QOL of the study participants}

Generally, 85\% of the survivors rated their QOL to be at least 'good' (Figure 1) and only $7.5 \%$ of them were dissatisfied with their health (Figure 2). Mean HR-QOL domain scores were compared between various sociodemographic and medical characteristics (Table 2). Pairwise comparison revealed married survivors to have higher physical health score compared to singles ( $\Delta=12.2$; $95 \% \mathrm{CI}=0.85-23.59, \mathrm{p}=0.033)$. We noted an order in the physical health score with occupation: full-timers scored

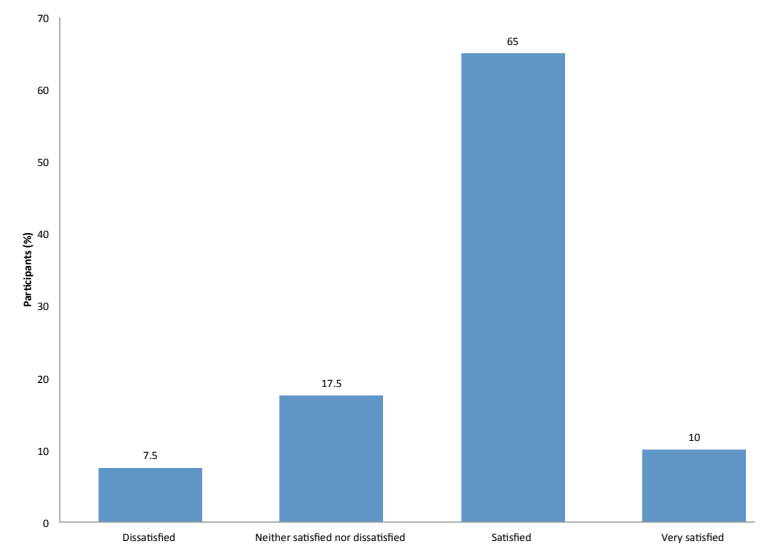

Figure 2. Study Participants'Satisfaction with Health

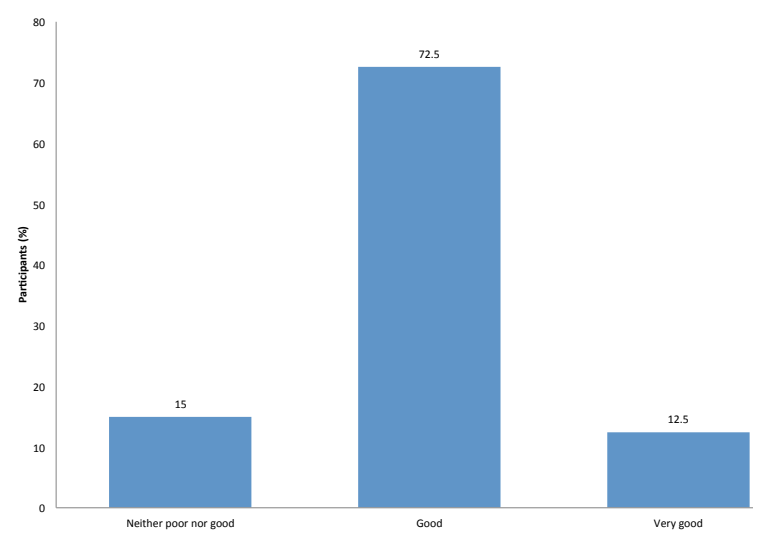

Figure 1. Study Participants' Self-Rating of QOL higher than part-timers $(\Delta=19.4 ; 95 \% \mathrm{CI}=5.62-32.23$, $\mathrm{p}=0.022$ ) and part-timers scored higher than unemployed survivors $(\Delta=13.1 ; 95 \% \mathrm{CI}=0.57-25.55, \mathrm{p}=0.038)$. Survivors who lived with family, ever given birth and diagnosed at an early stage of cancer also had significantly better physical health score.

Psychological domain score found to be significantly different between occupation and income groups $(\mathrm{p}<0.05)$. $\mathrm{BCa}$ survivors who have been working full-time have significantly higher psychological score than those who worked part-time $(\Delta=12.4 ; 95 \% \mathrm{CI}=0.80-23.96, \mathrm{p}=0.032)$, while those who earned the lowest $(<$ MYR 1,800$)$ had significantly lower psychological score than those who earned more than MYR4,500 ( $\Delta=-8.7$; 95\% CI=-15.86-$1.44, \mathrm{p}=0.015)$. Those who lived with family, ever given birth before and diagnosed at earlier stage had better psychological score $(\mathrm{p}<0.05)$. Women with no children had significantly lower psychological score compared to those who had one or two children $(\Delta=-9.3$; $95 \% \mathrm{CI}=-$ 17.00--1.57, $\mathrm{p}=0.015)$, and those who had three or more children $(\Delta=-9.6 ; 95 \% \mathrm{CI}=-17.62--1.60, \mathrm{p}=0.016)$.

In contrast, the only significant difference we could find in the social relationship domain score was between survivors who had ever given birth and who had never experienced it. Women who gave birth scored higher than those who never gave birth with acceptable significance (63.7 \pm 10.4 vs 55.1 $\pm 5.5, \mathrm{p}=0.048)$.

Married BCa survivors had higher mean environment score than singles $(\Delta=11.2 ; 95 \% \mathrm{CI}=1.95-20.42, \mathrm{p}=0.015)$. Similar to physical health and psychological domains, women who lived with their family, ever given birth and diagnosed at earlier stage of cancer had better environment score $(\mathrm{p}<0.05)$. Women with no children had significantly lower psychological score compared to those who had one or two children $(\Delta=-11.8 ; 95 \% \mathrm{CI}=-20.00--3.63, \mathrm{p}=0.003)$, and those who had three or more children $(\Delta=-9.4 ; 95 \%$ $\mathrm{CI}=-17.92--0.96$, $\mathrm{p}=0.027$ ).

Relationship between socio-demography, medical history and $H R-Q O L$

Multiple linear regression analysis was performed

Table 3. Multiple Linear Regression Analysis

\begin{tabular}{|c|c|c|c|c|c|c|}
\hline & Predictive factor & $\mathrm{r}$ & Beta & $\mathrm{t}$ & $\mathrm{P}$ & $95 \% \mathrm{CI}$ \\
\hline \multirow[t]{3}{*}{ Self-rate of QOL } & Living with family & 0.427 & -0.467 & -3.161 & 0.003 & $-1.757--0.381$ \\
\hline & Completion of treatment & 0.271 & 0.309 & 2.094 & 0.044 & $0.013-0.925$ \\
\hline & Adjusted $R^{2}=0.243, R^{2}=0.286, F=13.247 p<0.001$ & & & & & \\
\hline \multirow[t]{3}{*}{ Satisfaction with health } & Living with family & 0.562 & -0.605 & -4.647 & $<0.001$ & $-2.776--1.086$ \\
\hline & Ever given birth & 0.353 & 0.346 & 2.656 & 0.012 & $0.171-1.291$ \\
\hline & Adjusted $R^{2}=0.412, R^{2}=0.445, F=6.605, p=0.004$ & & & & & \\
\hline \multirow[t]{3}{*}{ Physical health } & Living with family & 0.586 & 0.437 & 2.955 & 0.006 & $3.464-18.783$ \\
\hline & Ever given birth & 0.62 & -0.359 & -2.426 & 0.021 & $-27.319--2.395$ \\
\hline & Adjusted $R^{2}=459, R^{2}=0.490, F=15.858, p<0.001$ & & & & & \\
\hline \multirow[t]{3}{*}{ Psychological } & Number of children & 0.487 & 0.467 & 3.262 & 0.003 & $1.030-4.446$ \\
\hline & Early stage of cancer & 0.337 & 0.299 & 2.084 & 0.045 & $0.131-10.795$ \\
\hline & Adjusted $R^{2}=0.285, R^{2}=0.326, F=7.990, p=0.001$ & & & & & \\
\hline \multirow[t]{2}{*}{ Social relationship } & Income more than MYR4,500 & 0.245 & 0.394 & 2.499 & 0.017 & $1.815-17.613$ \\
\hline & Adjusted $R^{2}=0.285, R^{2}=0.326, F=7.990, p=0.001$ & & & & & \\
\hline \multirow[t]{4}{*}{ Environment } & Age & 0.203 & 0.387 & 2.883 & 0.007 & $0.090-0.522$ \\
\hline & Income more than MYR4,500 & 0.275 & 0.345 & 2.526 & 0.017 & $1.269-11.842$ \\
\hline & Ever given birth & 0.502 & 0.484 & 3.609 & 0.001 & 4.463-16.027 \\
\hline & Adjusted $R^{2}=0.413, R^{2}=0.463, F=9.197, p<0.001$ & & & & & \\
\hline
\end{tabular}


to establish the relationship between socio-demography, medical history and HR-QOL of BCa survivors (Table 3). Living with family and completion of treatment were significant predictors of self-rated QOL $(\mathrm{p}<0.05)$. Both factors explained $28.6 \%$ variation in self-rated QOL in our sample. Giving birth and living with family were socio-demographic factors that were significant predictors of satisfaction with health, explaining $44.5 \%$ variation. Giving birth and living with family found to be strongly correlated with physical health score and also significantly predicted the score $(\mathrm{p}<0.05)$. Psychological health had moderate correlations with number of children and early cancer stage. These factors significantly predicted psychological health, explaining $32.6 \%$ of variation in psychological health score. Survivors' higher personal income (>MYR4,500) was the only significant predictor of social relationship, while age, income more than MYR4,500 and giving birth significantly predicted environment domain score, explaining $46.3 \%$ variation in the outcome.

\section{Discussion}

Given the rarity of $\mathrm{BCa}$ among males in general and particularly in this country, we recruited 40 female $\mathrm{BCa}$ survivors to our study. The mean age of our participants when surveyed was 57.45 years and majority of them were diagnosed between the age of 40 and 49 years old, which is in line with Malaysian data. Approximately $50 \%$ of Asian women studied by Yip and colleagues (Yip et al., 2006) were less than 50 years when diagnosed with $\mathrm{BCa}$ and Surakasula (Surakasula et al., 2014) reported the average age of women at diagnosis was 47.7 years. In contrast, $\mathrm{BCa}$ incidence in Western women less than 50 years was only 23\% (Smigal et al., 2006). This slight variation in age of diagnosis could be due to different culture or $\mathrm{BCa}$ knowledge among women which could have resulted in early or late diagnosis. However, women in this age group tend to have younger children and are still in the prime of their lives thus making it important to study their QOL. Eighty percent of our survivors were married, whereas previous studies (Dorjgochoo et al., 2010; Kumar et al., 2010; Kwan et al., 2010; Mohamed and Muhamad, 2013) reported between $63 \%$ and $88 \%$ participants to be married. Marital intimacy, relationship or partner's knowledge on $\mathrm{BCa}$, might have contributed to early detection.

Eighty five percent of our subjects had secondary to tertiary level education. Rimpela and colleagues (Rimpela and Pukkala, 1987) have related BCa with higher education, Bower et al. (2000) also observed that majority of patients were college graduates, while most of Gantz et al. (2003) subjects were post graduates. Many of Kwan et al. (2010) subjects (85\%) had post high school education and a local study by Yusuf et al. (2013) suggested most to have at least secondary level education, which is similar to our results. Higher education brings in better cancer knowledge with early seeking of medical help, resulting in higher detection rates.

Over a quarter of our survivors $(27.5 \%)$ were employed full or part-time, while the majority $(72.5 \%)$ was unemployed or retired. Previous studies suggested almost similar proportion of working survivors (Kumar et al., 2010; Kwan et al., 2010). One fourth of the respondents had income less than MYR1,800 (low income) and this percentage is much lower than ones reported in most previous studies (Bower et al., 2000; Ganz et al., 2003; Blanchard et al., 2004; Dorjgochoo et al., 2010; Kwan et al.,2010). Almost all of our respondents (95\%) were living with their families and this proportion is much higher than reported in previous studies (57-60\%) (Fairley TL et al., 2010; Ivanauskiene et al., 2014). The proportion of those who lived with family varied between our and other researches, which can be due to different family or social set ups, as in east most of people live in a joint family system contrary to the West.

Majority had given birth before (85\%), similar to previous report (Mohamed and Muhamad, 2013). However, $25 \%$ said they had no children implying child loss during or after childbirth. Although pregnancy has been suggested to be a protective factor for $\mathrm{BCa}$, this was not reflected in our data. This may be because protective factors included full term pregnancy at an earlier age, and full term pregnancies beyond 35 years of age do not confer the same protective effect according to (Kvale and Heuch, 1987).

Most of our respondents (82.5\%) were diagnosed at early stage, which is higher than data from the National Cancer Registry of Malaysia which showed that $58 \%$ of women presented with early stage BCa (Zainal Arrifin and Nor Saleha, 2011). Similarly previous studies indicated many were diagnosed at an early stage (Härtl K et al., 2003; Kwan et al., 2010). Above figures may reflect an increasing trend of cancer awareness in public with an early diagnosis. More than half of our survivors were diagnosed less than 5 years back, bearing similarity with Blanchard's study (Blanchard et al., 2004). Several of Fairly's (Fairley et al., 2010) participants (48.2\%) were diagnosed within last 5 years, whereas most of the subjects in Henderson's study (Henderson et al., 2012) were detected over a year, but some were diagnosed between 7 - 12months. Indicating that many have recovered recently and might be in early recovery phase, experiencing cancer related physical or psychological ordeals.

In our study, living arrangement was correlated with many aspects of QOL. Living with family predicted self -rated QOL, satisfaction with health and physical health, and those who stayed with their family had higher mean physical health, psychological and environment score. Each ethnic group has its own specific cultural and coping mechanisms. Our participants were mostly Chinese, Cheng and colleagues (Cheng et al., 2013) studied BCa survivors in China, and stated that the primary source of emotional support came from family, and a study among Chinese and Korean American BCa (Lim and AshingGiwa, 2013) reported a better HRQOL with family communication and flexibility. This supports our findings that those living with family had better outcomes.

High income $(>$ MYR4,500) positively predicted social relationship and environment score. Women who reported lower income $(<$ MYR1,800) had lowest psychological score. Kwan et al. (2010) highlighted a direct association between social well-being scores and income. In addition, 
Ivanauskienè and colleagues (Ivanauskiene et al., 2014) also stated interaction between financial status and emotions.

Giving birth predicted survivors' satisfaction with health, physical health and environment domain scores, and those who have given birth had higher mean scores for all HRQOL domains. Number of children also predicted psychological score; more children resulted in a better score. Women without children had lower psychological and environment score. A Taiwanese study suggested family factor as a predictor of QOL satisfaction while number of children was significantly associated with QOL among survivors (Lee et al., 2001).

Our study also found that women who were diagnosed at early stage of $\mathrm{BCa}$ had better physical health, psychological and environment score. Early stage cancer diagnosis has been associated with higher physical and emotional well-being scores (Kwan et al., 2010). However, Shanghai Breast Cancer Survival Study (Lu et al., 2009) showed that advanced disease stage was not associated with overall QOL or majority of well-being domains, except poor social well-being at 6 months post diagnosis.

Other factors which predicted or associated with HRQOL were treatment completion, age, marital status and full-time employment. Treatment completion predicted self-rated QOL, with those who completed the treatment had better QOL. Age significantly predicted the environment domain score. Our study found higher mean score of physical health domain in married survivors, concurring with previous findings (Ivanauskiene et al., 2014; Kwan et al., 2010), which reported full time workers to have better physical health and psychological score.

Limitation The BCSG JB mainly comprises Chinese and do not represent other ethnic groups, which could affect study's quality and generalization. Due to cross sectional study design and short duration, those who suffered before or after study could have been left out, necessitating study of longer duration.

In conclusion, the findings from our survey has revealed that our Malaysian BCa survivors cope better in all four domains if they were married, lived with family, had children and were employed. Furthermore, this study adds to the beginning of the development of long term interventions for these survivors based on the factors identified. This should be preferably done in a bigger group and cross-sectional across different ethnic group. However, the current study shows a statistical significant correlation in some aspects but there were some inconclusive findings when it was compared against other psychosocial variables, and it is difficult to generalise these findings. Larger sample size and more of qualitative data will further help the future researchers to adequately identify the specific needs of each ethnic group. These limitations should be considered when interpreting the study findings.

\section{References}

Abdullah NA, Wan Mahiyuddin WR, Muhammad NA et al (2013). Survival rate of breast cancer patients in Malaysia: a population-based study. Asian Pac J Cancer Prev, 14,
4591-4.

Blanchard CM, Stein KD, Baker F et al (2004). Association between current lifestyle behaviors and health-related quality of life in breast, colorectal, and prostate cancer survivors. Psychology Health, 19, 1-13.

Bower JE, Ganz PA, Desmond KA et al (2000). Fatigue in breast cancer survivors: occurrence, correlates, and impact on quality of life. J Clin Oncol, 18, 743-53.

Cappiello M, Cunningham RS, Knobsf MT et al (2007). Breast cancer survivors: information and support after treatment. Clinical Nurs Res, 16, 278-93.

Cheng H, Sit JW, Chan CW et al (2013). Social support and quality of life among Chinese breast cancer survivors: findings from a mixed methods study. Eur J Oncol Nurs, 17, 788-96.

Dorjgochoo T, Kallianpur A, Zheng Y et al (2010). Impact of menopausal symptoms on quality of life 6 months after systemic breast cancer treatment: results from the Shanghai Breast Cancer Survival Study. Breast Cancer Res Treat, 119, 725-35.

Epping-Jordan JE, Compas BE, Osowiecki DM et al (1999). Psychological adjustment in breast cancer: processes of emotional distress. Health Psychol, 18, 315-26.

Fairley TL, Hawk H and Pierre S (2010). Health behaviors and quality of life of cancer survivors in Massachusetts, 2006: data use for comprehensive cancer control. Prev Chronic Dis, 7, 9 .

Ganz PA, Greendale GA, Petersen L et al (2003). Breast cancer in younger women: reproductive and late health effects of treatment. J Clin Oncol, 21, 4184-93.

Härtl K, Janni W, Kästne H et al (2003). Impact of medical and demographic factors on long-term quality of life and body image of breast cancer patients. Ann Oncol, 14, 1064-71.

Henderson S, Holland J, McGrellis S et al (2012). Storying qualitative longitudinal research: sequence, voice and motif. Qual Res, 12, 16-34.

Ibrahim NI, Dahlui M, Aina EN et al (2012). Who are the breast cancer survivors in Malaysia? Asian Pac J Cancer Prev, 13, 2213-8.

Ivanauskiene R, Padaiga Z, Simoliuniene R et al (2014). Wellbeing of newly diagnosed women with breast cancer: which factors matter more? Support Care Cancer, 22, 519-26.

Koch L, Jansen L, Herrmann A et al (2013). Quality of life in long-term breast cancer survivors - a 10-year longitudinal population-based study. Acta Oncol, 52, 1119-28.

Kumar Sm Shaikh AJ, Khalid S et al (2010). Influence of patient's perceptions, beliefs and knowledge about cancer on treatment decision making in Pakistan. Asian Pac J Cancer Prev, 11, 251-5.

Kvale $\mathrm{G}$ and Heuch I (1987). A prospective study of reproductive factors and breast cancer. II. Age at first and last birth. Am $J$ Epidemiol, 126, 842-50.

Kwan ML, Ergas IJ, Somkin CP et al (2010). Quality of life among women recently diagnosed with invasive breast cancer: the Pathways Study. Breast Cancer Res Treat, 123, 507-24.

Lee HL, Ku NP, Dow WJ et al (2001). Factors related to quality of life in breast cancer patients receiving chemotherapy. $J$ Nurs Res, 9, 57-68.

Lim JW and Ashing-Giwa KT (2013). Is family functioning and communication associated with health-related quality of life for Chinese-and Korean-American breast cancer survivors? Qual Life Res, 22, 1319-29.

Lu W, Cui Y, Chen X et al (2009). Changes in quality of life among breast cancer patients three years post-diagnosis. Breast Cancer Res Treat, 114, 357-69.

Mohamed NA and Muhamad M (2013). Older women breast 

cancer survivors: decision making, sources of information and wellness activities in Malaysia. Asian Pac J Cancer Prev, 14, 2043-8.

National Cancer Registry (2007). National Cancer Registry Report: Malaysia Cancer Statistic Data and Figure.

Rimpela AH and Pukkala EI (1987). Cancers of affluence: positive social class gradient and rising incidence trend in some cancer forms. Soc Sc Med, 24, 601-6.

Smigal C, Jemal A, Ward E et al (2006). Trends in breast cancer by race and ethnicity: update 2006. CA Cancer J Clin, 56, 168-83.

Surakasula A, Nagarjunapu GC and Raghavaiah KV (2014). A comparative study of pre- and post-menopausal breast cancer: Risk factors, presentation, characteristics and management. J Res Pharm Pract, 3, 12-8.

Taib NA, Akmal M, Mohamed I et al (2011). Improvement in survival of breast cancer patients - trends over two time periods in a single institution in an Asia Pacific country, Malaysia. Asian Pac J Cancer Prev, 12, 345-9.

Thewes B, Butow P, Girgis A et al (2004). The psychosocial needs of breast cancer survivors; a qualitative study of the shared and unique needs of younger versus older survivors. Psychooncol, 13, 177-89.

Wenzel LB, Fairclough DL, Brady MJ et al (1999). Age-related differences in the quality of life of breast carcinoma patients after treatment. Cancer, 86, 1768-74.

Yip CH, Taib NA and Mohamed I (2006). Epidemiology of breast cancer in Malaysia. Asian Pac J Cancer Prev, 7, 369-74.

Yusuf A, Ahmad Z and Keng SL (2013). Quality of life in Malay and Chinese women newly diagnosed with breast cancer in Kelantan, Malaysia. Asian Pac J Cancer Prev, 14, 435-440.

Zainal Arrifin O, Nor Saleha IT (2011). Malaysian Cancer Statistics Data and Figure 2007 (Putrajaya, National Cancer Registry, Ministry of Health, Malaysia). 